\title{
VORTEX TUBE AIR COOLING: THE EFFECT ON SURFACE ROUGHNESS AND POWER CONSUMPTION IN DRY TURNING
}

\author{
Zahari Taha ${ }^{1}$, H.A. Salaam,", T.M.Y.S. Tuan Ya $^{2}$, S.Y. Phoon ${ }^{1}$, C.F. $\operatorname{Tan}^{3}$ and \\ M.A. Akiah ${ }^{4}$ \\ ${ }^{1}$ Faculty of Manufacturing Engineering, Universiti Malaysia Pahang, \\ 26600 Pekan, Pahang, Malaysia \\ ${ }^{2}$ Faculty of Mechanical Engineering, Universiti Malaysia Pahang, \\ 26600 Pekan, Pahang, Malaysia \\ ${ }^{3}$ Faculty of Mechanical Engineering, Universiti Teknikal Malaysia Melaka, \\ Hang Tuah Jaya, 76100, Durian Tunggal, Melaka \\ ${ }^{4}$ Faculty of Manufacturing Engineering, Universiti Teknikal Malaysia Melaka, \\ Hang Tuah Jaya, 76100, Durian Tunggal, Melaka \\ *Email: hadisalaam@ump.edu.my
}

\begin{abstract}
There has been increased awareness of the need to reduce environmental impacts in the last 10 years. The manufacturing industry is striving to reduce environmental impacts by introducing new materials with better characteristics, that consume less processing power and use smaller amounts of processing coolant. The main objective of this paper is to study the effect of the Ranque-Hilsch vortex cooling tube on power consumption and surface roughness quality in the turning process when machining mild steel material with a coated carbide cutting tool. The machining parameters involved in the experiment are cutting speed, feed rate and depth of cut. The cutting speed is fixed at $160 \mathrm{~m} / \mathrm{min}$ while the feed rate and the depth of cut are varied. The feed rates used are $0.10,0.18$ and $0.28 \mathrm{~mm} / \mathrm{rev}$, while the depth of cut is varied from 1.0 to $4.0 \mathrm{~mm}$. During the machining process, the cutting temperatures are measured using an infrared thermometer and the power consumption is measured using a Prova 6830 power and harmonics analyzer. The surface roughnesses of the machined parts are measured using a surface roughness tester. The results show that cooling using Ranque-Hilsch vortex tube air cooling reduces the cutting temperature, but the power consumption and surface roughness are better under ambient conditions except at $0.28 \mathrm{~mm} / \mathrm{rev}$ feed rate.
\end{abstract}

Keywords: Ranque-Hilsch vortex tube (RHVT); turning process; power consumption; surface roughness.

\section{INTRODUCTION}

The extensive use of cutting fluids in machining has significantly improved the productivity and quality of parts produced by many machining industries. However, the negative effects of cutting fluids on manufacturing cost, human health and the environment have become a serious problem. Thus there is a strong need to reduce the use of coolants. The application of Ranque-Hilsch vortex tubes (RHVT) in dry turning can be an alternative solution to the above problems. Turning is a process to produce straight, conical, curved or grooved workpieces by using a single point cutting process where the cylindrical workpiece material is rotated at the chuck and a cutting tool removes layer(s) of materials as it moves to the left (Kalpakjian \& Schmid, 2006). In 
this cutting operation, the surface finish quality is important since it reflects the quality of a product (Thomas \& Beauchamp, 2003). Research on the turning process has been conducted by many researchers with different materials and methods (Yusuf et al., 2011). There are many types of cutting fluids in the market which cool down the cutting zone, reduce friction and wear, and remove chips from the workpiece (Aznijar et al., 2010; El Baradie, 1996). Thus, the application of cutting fluids can significantly improve the quality of the surface finish and extend the life of the cutting tool. However, the economic cost assessment and justification and the proper selection of the cutting fluids are not always as rational as they could be (El Baradie, 1996). There are specific coolants developed for specific workpiece materials to increase the cutting tool performance, but some of them are harmful to humans and the environment because of their toxicity (Kalpakjian \& Schmid, 2006). Additionally, an effort towards reducing power consumption in cutting will lead to a more sustainable approach to machining. In this study, the use of the Ranque-Hilsch vortex tube (RHVT) is explored as an alternative to cooling in the turning process. The Ranque-Hilsch vortex tube (RHVT) is a simple, low cost, small and lightweight device which uses high velocity compressed air as a power source. It has no moving parts and produces hot air at one end and cold air at the other end. It is commonly made from a durable material such as stainless steel and does not require any electricity or chemicals to function (Exair Corporation, 2013). Due to these advantages, vortex tubes have been used in many applications such as cooling and heating of various operations, thermal tests, dehumidification, gas liquefaction, ice production and mixture separation (Xue, Arjomandi, \& Kelso, 2011).

The vortex tube was invented accidentally by George Ranque, a French physics student in 1928. At that time, Ranque was conducting an experiment with the vortextype pump that he had developed, when he noticed warm air exhausting from one end and cold air from the other end. After observing this phenomenon, Ranque soon forgot about his pump and started a small firm to exploit the commercial potential of this strange device that produced both cold and hot air without involving any moving parts. However, it soon failed after he presented a paper on his vortex tube to a scientific society in France in 1933, where it was met with disbelief and disinterest (Yilmaz et al., 2009), and the vortex tube slipped into obscurity until 1945, when Rudolph Hilsch, a German physicist, published a widely read scientific paper on the device (Exair Corporation, 2013). The basic construction of the RHVT consists of an input air inlet, cold air exit, hot air, exit vortex spin chamber, hollow cylinder and control valve, as shown in Figure 1.

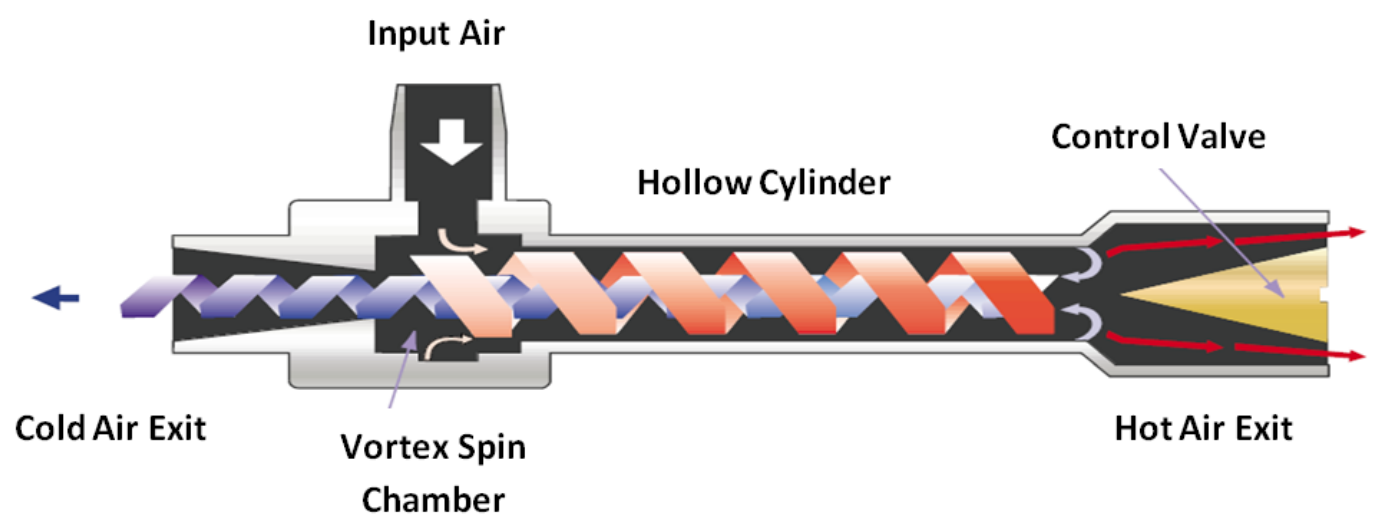

Figure 1. Vortex tube diagram (Source: Exair Corporation, 2013). 
Generally, a supply of compressed air is injected tangentially through the air inlet. The air travels into the vortex spin chamber where it is changed into a turbulence flow and then travels into the hollow cylinder and goes out at the hot air exit located at the periphery as hot dry air. Some of the air is forced back into the hollow cylinder and a second turbulence flow occurs inside the first turbulence flow and goes out at the cold air exit as a cold air. The control valve at the hot air exit controls the amount of air out at both ends. RHVTs can be classified into two categories (Yilmaz et al., 2009): counter-flow and uni-flow. The difference between these two is the location of the hot and cold air exits. For counter-flow RHVT, the hot and cold air exits are located at opposite ends, while in the uni-flow version the hot and cold air exits are located at the same end, as shown in Figure 2.

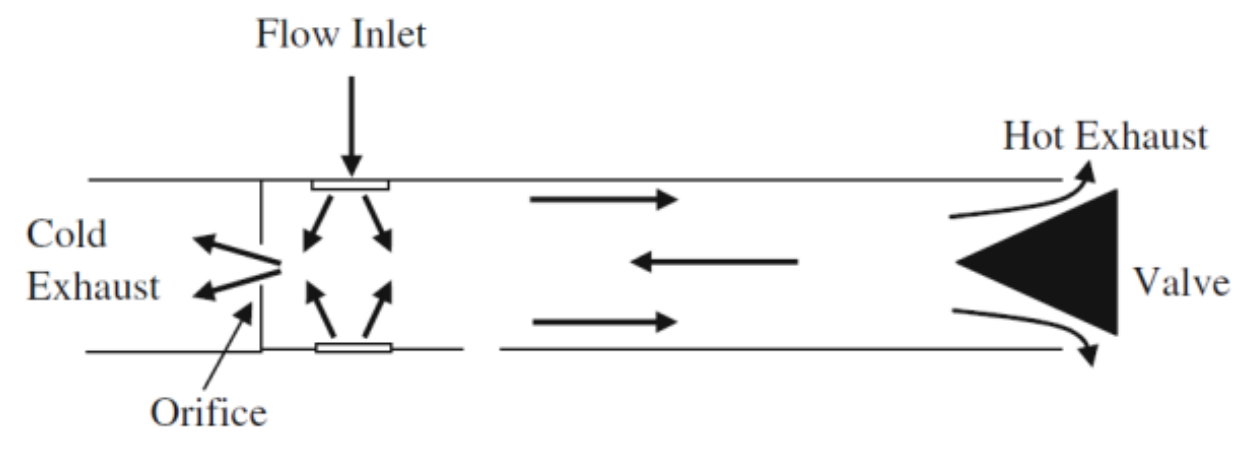

(a)

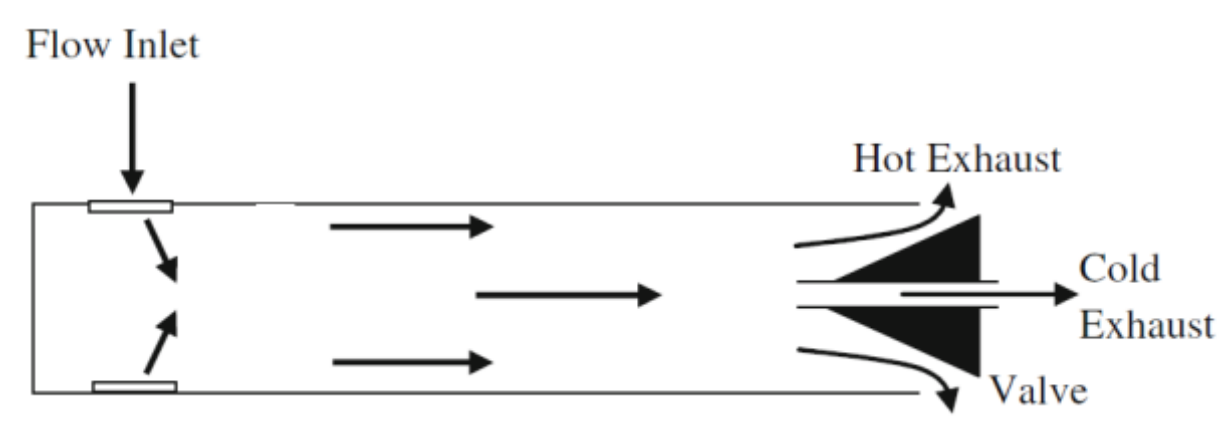

(b)

Figure 2. (a) Counter flow and (b) uni-flow vortex tube (Yilmaz et al., 2009).

Much research has been done using different types of RHVT. Based on a review of these studies, counterflow RHVT is the most popular variant. Balmer (1988), Crocker, White, and Bremer (2003), Gao et al. (2005), Aljuwayhel, Nellis, and Klein (2005), Behera et al. (2005), Aydin and Baki (2006), Dincer, Baskaya, and Uysal (2008), Behera et al. (2008), Yalcin, Ozgur, and Koru (2009), Dincer et al. (2009), Kirmaci (2009), Secchiaroli et al. (2009), Markal, Aydin, and Acvi (2010), Xue et al. (2010, 2011), Michalek et al. (2011) and Liew, Michalek, and Kuerten (2011) all used counterflow RHVT in conducting their research experiments. RHVTs have been used widely in many applications such as in refrigeration systems (Dincer et al., 2009; Kirmaci, 2009), in chemical, gas and oil and gas research (Khodorkov et al., 2003) and in advanced space transportation systems (Crocker et al., 2003). Besides that, Aydin and Baki (2006) applied RHVT in energy separation research, and Yalcin et al. (2009) 
applied RHVT in milling machining. Gao et al. (2005) used RHVT in the cryogenics area while Balmer (1988), Markal et al. (2010), and Xue et al. (2010, 2011) applied RHVT in experimentation in thermal and fluid sciences. Eiamsa-ard and Promvonge (2008) applied RHVT research in the renewable energy area. The main objective of this paper is to illustrate the machining performance of the dry cooling method using the Ranque-Hilsch vortex tube (RHVT) and ambient air. The structure, working principles and types of RHVT are presented in this paper. The experimental setup and machining performance are discussed in brief.

\section{EXPERIMENTAL SETUP}

In this experiment, a conventional turning machine was used to machine mild steel material $38 \mathrm{~mm}$ in diameter and $100 \mathrm{~mm}$ in length. The length of the workpiece being machined was $20 \mathrm{~mm}$. The cutting tool insert used was a Tungaloy tnmg $160408 \mathrm{tmt}$ 9125 coated carbide together with a Mitsubishi mtjnr tool holder. Before the machining took place, the percentages of mild steel chemical composition were checked using a spectrometer. Results of the chemical composition of mild steel used in the experiment are shown in Table 1. The main chemical composition of mild steel is iron $(\mathrm{Fe})$ which contains about $98.5 \%$ of the total chemical compositions; followed by manganese $(\mathrm{Mn})$ $0.546 \%$, carbon $0.271 \%$, Si $0.023 \%$ etc; this is also known as A36 steel.

Table 1. Results of chemical composition of mild steel used in the experiment.

\begin{tabular}{cccc}
\hline $\begin{array}{c}\text { Chemical } \\
\text { Composition }\end{array}$ & $\%$ & $\begin{array}{c}\text { Chemical } \\
\text { Composition }\end{array}$ & $\%$ \\
\hline $\mathrm{Fe}$ & 98.5 & $\mathrm{Al}$ & 0.0082 \\
$\mathrm{C}$ & 0.217 & $\mathrm{Co}$ & $<0.01$ \\
$\mathrm{Si}$ & 0.223 & $\mathrm{Cu}$ & 0.211 \\
$\mathrm{Mn}$ & 0.546 & $\mathrm{Nb}$ & $<0.005$ \\
$\mathrm{P}$ & $<0.01$ & $\mathrm{Ti}$ & 0.005 \\
$\mathrm{~S}$ & $<0.01$ & $\mathrm{~V}$ & $<0.005$ \\
$\mathrm{Cr}$ & 0.0406 & $\mathrm{~W}$ & $<0.0250$ \\
$\mathrm{Mo}$ & $<0.01$ & $\mathrm{~Pb}$ & $<0.005$ \\
$\mathrm{Ni}$ & 0.0853 & & \\
\hline
\end{tabular}

The machining process was conducted under two different dry cooling methods: ambient air and compressed air through the RHVT. For this experiment, the cutting parameter used was a spindle speed of 100 and $160 \mathrm{~m} / \mathrm{min}$, feed rate of $0.10,0.18$ and $0.28 \mathrm{~mm} / \mathrm{rev}$ and a variation of depth of cut from $1.0 \mathrm{~mm}$ up to $4.0 \mathrm{~mm}$. The surface finished quality was measured using a Mahr surface Perthometer. A Prova 6830 Power and Harmonic Analyzer was used to monitor power consumption during the machining operation and the specific energy consumption was calculated using Eq. 1 as proposed by Zahari et al. (2010).

$$
\text { Specific energy consumption }(\mathrm{SEC})=\frac{\text { Power consumption }(\mathrm{kWh})}{\text { Volume of material removed }\left(\mathrm{mm}^{3}\right)}
$$


Figure 3 shows the connection of the power analyzer used in the experiment. Design of experiment was used to determine the effects of cutting parameters on the surface roughness, based on the recommendations by Kalpakjian and Schmid (2006).
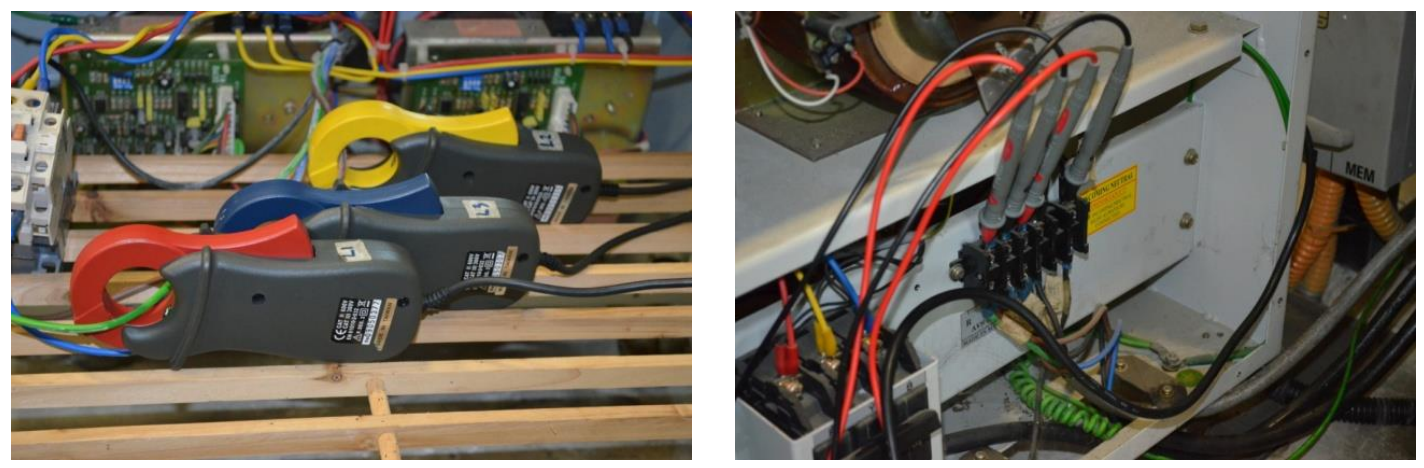

Figure 3. Connection of Prova 6830 Power and Harmonic Analyzer setup used in the experiment during machining.

\section{RESULTS AND DISCUSSION}

The results using RHVT as a cooling medium when the cutting speed was fixed at 160 $\mathrm{m} / \mathrm{min}$, with feed rates of $0.10,0.18$ and $0.28 \mathrm{~mm} / \mathrm{rev}$ and the depth of cut varied from $1.0 \mathrm{~mm}$ to $4.0 \mathrm{~mm}$ are shown in Table 2 . When the cutting speed was fixed and the feed rate and depth of cut were increased, the average cutting temperature and power consumption increased gradually. The surface quality performance was better at the lower feed rate than at the higher feed rate.

Table 2. Machining performance results using RHVT as a cooling method.

\begin{tabular}{ccccccc}
\hline $\begin{array}{c}\text { Cutting } \\
\text { parameter }\end{array}$ & $\begin{array}{c}\text { Depth } \\
\text { of cut } \\
(\mathrm{mm})\end{array}$ & $\begin{array}{c}\text { Average } \\
\text { cutting } \\
\text { temperature } \\
\left({ }^{\circ} \mathrm{C}\right)\end{array}$ & $\begin{array}{c}\text { Power } \\
\text { consumption } \\
(\mathrm{kWh})\end{array}$ & $\begin{array}{c}\text { Average } \\
\text { surface } \\
\text { roughness } \\
(\mu \mathrm{m})\end{array}$ & $\begin{array}{c}\text { Material } \\
\text { removed } \\
\left(\mathrm{mm}^{3}\right)\end{array}$ & $\begin{array}{c}\text { SEC } \\
\left(\mathrm{kWh} / \mathrm{mm}^{3}\right) \\
\left(\mathrm{x} 10^{6}\right)\end{array}$ \\
\hline Cutting & & & & & & \\
speed: & 1.0 & 32.50 & 0.0111 & 3.602 & 9299.11 & 1.194 \\
$160 \mathrm{~m} / \mathrm{min}$ & 2.0 & 38.50 & 0.0119 & 3.601 & 18095.57 & 0.6576 \\
Feed rate: & 3.0 & 45.30 & 0.0135 & 3.004 & 26389.37 & 0.5116 \\
$0.10 \mathrm{~mm} / \mathrm{rev}$ & 4.0 & 53.80 & 0.0140 & 2.354 & 34280.52 & 0.4084 \\
\hline Cutting & & & & & & \\
speed: & 1.0 & 35.50 & 0.0145 & 5.564 & 9299.11 & 1.559 \\
$160 \mathrm{~m} / \mathrm{min}$ & 2.0 & 42.50 & 0.0170 & 3.572 & 18095.57 & 0.9394 \\
Feed rate: & 3.0 & 54.50 & 0.0175 & 2.694 & 26389.37 & 0.6631 \\
$0.18 \mathrm{~mm} / \mathrm{rev}$ & 4.0 & 58.90 & 0.0217 & 2.324 & 34280.52 & 0.6331 \\
\hline Cutting & & & & & & \\
speed: & 1.0 & 34.20 & 0.0223 & 6.495 & 9299.11 & 2.3981 \\
$160 \mathrm{~m} / \mathrm{min}$ & 2.0 & 52.80 & 0.0220 & 4.178 & 18095.57 & 1.2158 \\
Feed rate: & 3.0 & 55.70 & 0.0254 & 4.292 & 26389.37 & 0.9625 \\
$0.28 \mathrm{~mm} / \mathrm{rev}$ & 4.0 & 77.00 & 0.0267 & 3.018 & 34280.52 & 0.7789 \\
\hline
\end{tabular}


Table 3. Machining performance results using ambient air as a cooling method.

\begin{tabular}{ccccccc}
\hline $\begin{array}{c}\text { Cutting } \\
\text { parameter }\end{array}$ & $\begin{array}{c}\text { Depth } \\
\text { of cut } \\
(\mathrm{mm})\end{array}$ & $\begin{array}{c}\text { Average } \\
\text { cutting } \\
\text { temperature } \\
\left({ }^{\circ} \mathrm{C}\right)\end{array}$ & $\begin{array}{c}\text { Power } \\
\text { consumption } \\
(\mathrm{kWh})\end{array}$ & $\begin{array}{c}\text { Average } \\
\text { surface } \\
\text { roughness } \\
(\mu \mathrm{m})\end{array}$ & $\begin{array}{c}\text { Material } \\
\text { removed } \\
\left(\mathrm{mm}^{3}\right)\end{array}$ & $\begin{array}{c}\text { SEC } \\
\left(\mathrm{kWh} / \mathrm{mm}^{3}\right) \\
\left(\mathrm{x} 10^{6}\right)\end{array}$ \\
\hline Cutting & & & & & & \\
speed: & 1.0 & 31.30 & 0.0091 & 3.916 & 9299.11 & 0.9786 \\
$160 \mathrm{~m} / \mathrm{min}$ & 2.0 & 51.50 & 0.0101 & 3.717 & 18095.57 & 0.5581 \\
Feed rate: & 3.0 & 57.00 & 0.0125 & 2.993 & 26389.37 & 0.4737 \\
$0.10 \mathrm{~mm} / \mathrm{rev}$ & 4.0 & 97.50 & 0.0137 & 2.402 & 34280.52 & 0.3996 \\
\hline Cutting & & & & & & \\
speed: & 1.0 & 38.90 & 0.0140 & 4.700 & 9299.11 & 1.5055 \\
$160 \mathrm{~m} / \mathrm{min}$ & 2.0 & 50.80 & 0.0164 & 3.651 & 18095.57 & 0.9063 \\
Feed rate: & 3.0 & 59.00 & 0.0196 & 2.529 & 26389.37 & 0.7427 \\
$0.18 \mathrm{~mm} / \mathrm{rev}$ & 4.0 & 101.80 & 0.0215 & 1.967 & 34280.52 & 0.6272 \\
\hline Cutting & & & & & & \\
speed: & 1.0 & 39.90 & 0.0239 & 7.105 & 9299.11 & 2.5701 \\
$160 \mathrm{~m} / \mathrm{min}$ & 2.0 & 54.50 & 0.0238 & 5.589 & 18095.57 & 1.3152 \\
Feed rate: & 3.0 & 58.10 & 0.0248 & 3.439 & 26389.37 & 0.9298 \\
$0.28 \mathrm{~mm} / \mathrm{rev}$ & 4.0 & 137.60 & 0.0281 & 2.155 & 34280.52 & 0.8197 \\
\hline
\end{tabular}

The specific energy consumption decreased as the depth of cut increased at a fixed cutting speed and feed rate. The same trend was observed for machining in ambient temperature, as shown in Table 3 . The specific energy consumption reduced as the depth of cut and feed rate increased. It can be seen that machining in ambient temperature is generally better than with vortex air cooling.

Figure 4 shows the graph of cutting temperature at the different depths of cut, feed rates and cooling methods. The cutting temperature in ambient air was higher than when using RHVT. When using the RHVT, the cutting temperature dropped almost $50 \%$. This was because the RHVT supplies a high velocity low temperature air which cools down the heat generated at the cutting areas.

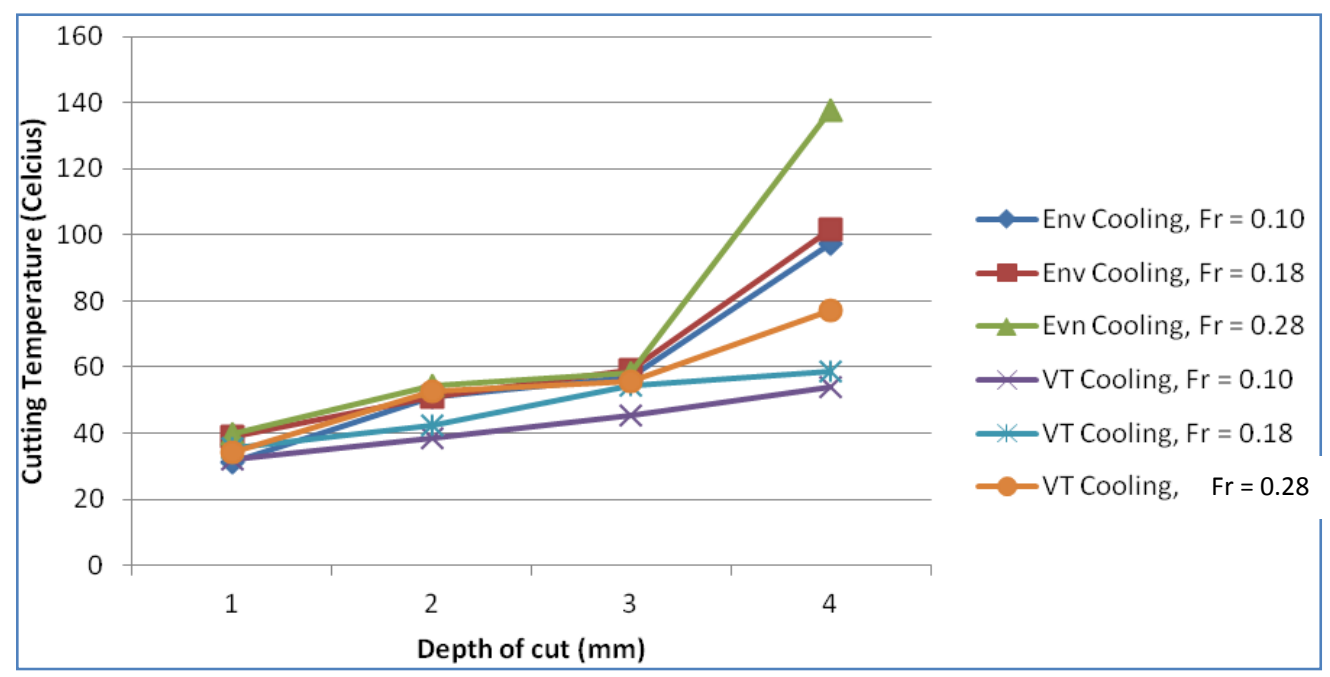

Figure 4. Cutting temperature performance when cutting workpiece with respect to different depths of cut, feed rates $\left(\mathrm{F}_{\mathrm{r}}\right)$ and cooling methods. 
Figure 5 shows the graph of surface roughness with respect to different depths of cut, feed rates and cooling methods. In general, the surface roughness quality is lower for RHVT cooling compared to the ambient air cooling. This is because the introduction of low temperature air at the cutting area makes the workpiece surface solidify quickly in a short time. Besides that, the introduction of low temperature air during cutting will cause quenching of the surface being heat treated (Kalpakjian \& Schmid, 2006). The introduction of air alone in cooling the cutting area does not give satisfactory results in machining (Sharma, Dogra, \& Suri, 2009).

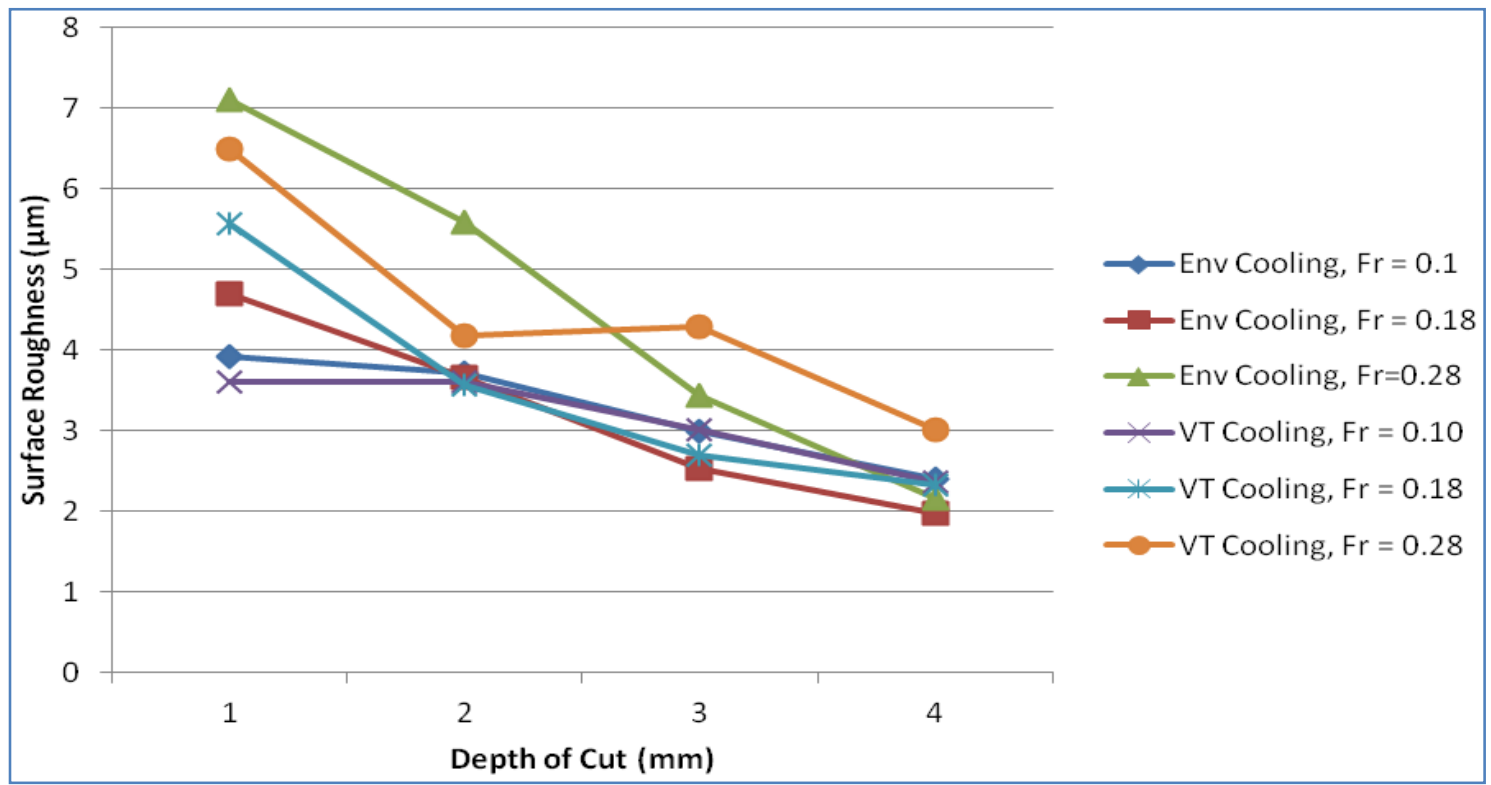

Figure 5. Surface roughness quality performance with respect to different depths of cut, feed rates and cooling methods.

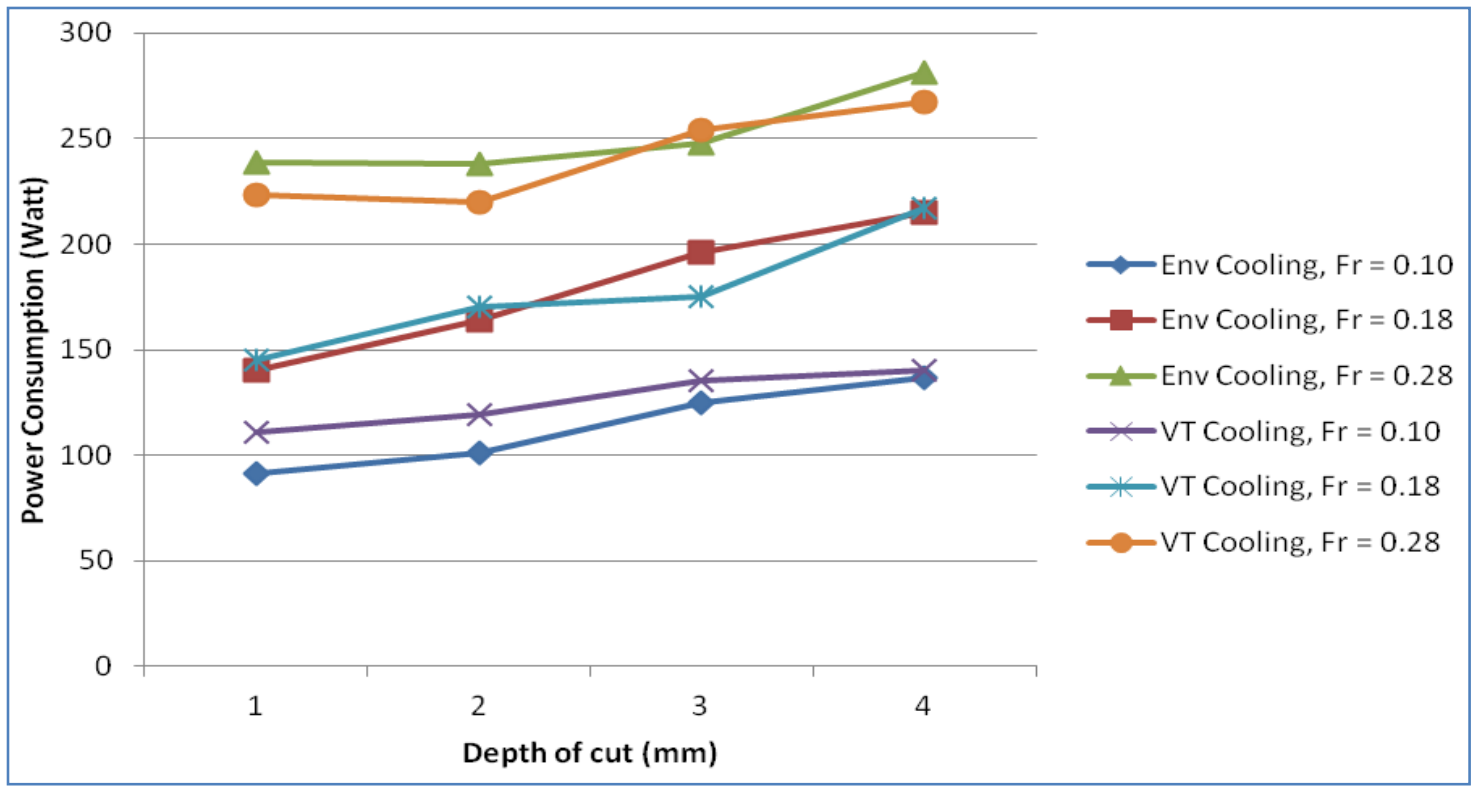

Figure 6. Power consumption performance with respect to different depths of cut, feed rates and cooling methods. 
Figure 6 shows the graph of power consumption with respect to different depths of cut, feed rates and cooling methods. In general, higher power consumption was observed when using RHVT as a cooling medium compared to ambient air, except at a feed rate of $0.28 \mathrm{~mm} / \mathrm{rev}$. When compressed air moves inside the vortex tube, it travels to the hot air exit first, and then to the cold air exit. When entering the hot air exit, dry high pressure air will be produced and then exit as cold and totally dry air. When this air hits the cutting area, more power is needed since the friction force is higher due to the lack of lubrication effect (Sharma et al., 2009). With proper adjustment of the nozzle, the outcome of using vortex tube air cooling can be better (Sharma et al., 2009).

\section{CONCLUSIONS}

Based on the experiment conducted, dry machining in ambient air temperature performs better than using RHVT. Overall, the surface roughness, power consumption and specific energy consumption performance are better, except at a feed rate of 0.28 $\mathrm{mm} / \mathrm{rev}$. Lubrication is more important at low cutting speed, whereas the cooling effect is more important at higher cutting speed due to the large increase in heat generated by the chip removal process.

\section{ACKNOWLEDGMENTS}

The authors would like to thank the MTUN Secretariat for financial support (RDU121223) and the Faculty of Mechanical Engineering, Universiti Malaysia Pahang (UMP).

\section{REFERENCES}

Aljuwayhel, N. F., Nellis, G. F, \& Klein, S. A. (2005). Parametric and internal study of the vortex tube using CFD model. International Journal of Refrigeration, 28, 442-450.

Aydin, O. \& Baki, M. (2006). An experimental study on the design parameters of a counterflow vortex tube. Energy, 31, 2763-2772.

Aznijar, A. Y., Taha, Z., \& Almanar, I. P. (2010). A review of cooling in high speed machining (HSM) of mold and die steel. Scientific Research and Essays, 5, 412427.

Balmer, R. T. (1988). Pressure driven Ranque-Hilsch temperature separation in liquids. Journal of Fluids Engineering, 110, 161-164.

Behera, U., Paul, P. J., Kasthurirengan, S., Karunanithi, R., \& Ram, S. N. (2005). CFD analysis and experimental study investigations towards optimizing the parameters of Ranque-Hilsch vortex tube. International Journal of Heat and Mass Transfer, 48, 1961-1973.

Behera, U., Paul, P. J., Dinesh, K., \& Jacob, S. (2008). Numerical investigation on flow behaviour and energy separation in Ranque-Hilsch vortex tube. International Journal of Heat and Mass Transfer, 51, 6077-6089.

Crocker, A. M., White, S. M., \& Bremer, F. (2003). Experimental results of a vortex tube air separator for advanced space transportation. $39^{\text {th }}$ Joint Propulsion Conference \& Exhibit, Huntsville, AL, 2-23 July 2003. 
Dincer, K., Baskaya, S., \& Uysal, B. Z. (2008). Experimental investigation of the effects of length to diameter ratio and nozzle number on the performance of counter flow Ranque-Hilsch vortex tubes. Heat Mass Transfer, 44, 367-373.

Dincer, K., Baskaya, S., Uysal, B. Z., \& Ucgul, I. (2009). Experimental investigation of the performance of a Ranque-Hilsch vortex tube with regard to a plug located at the hot outlet. International Journal of Refrigeration, 32, 87-94.

Eiamsa-ard, S. \& Promvonge, P. (2008). Review of Ranque-Hilsch effects in vortex tubes. Renewable \& Sustainable Energy Reviews, 12, 1822-1842.

El Baradie, M. A. (1996). Cutting fluids: Part I: Characterisation. Journal of Materials Processing Technology, 56, 786-797.

Exair Corporation (2013). Information on www.exair.com (Accessed 5 December 2012).

Gao, C. M., Bosschaart, K. J., Zeegers, J. C. H., \& De Waele, A. T. A. M. (2005). Experimental study on a simple Ranque-Hilsch vortex tube. Cryogenics, 45, 173-183.

Kalpakjian, S. \& Schmid, S. R. (2006). Manufacturing Engineering and Technology $\left(5^{\text {th }}\right.$ ed.). New Jersey: Pearson Prentice Hall.

Khodorkov, I. L., Poshernev, N. V., \& Zhidkov, M. A. (2003). The vortex tube - A universal device for heating, cooling, cleaning and drying gases and separating gas mixtures. Chemical and Petroleum Engineering, 39, 24-27.

Kirmaci, V. (2009). Exergy analysis and performance of a counter flow Ranque-Hilsch vortex tube having various nozzle numbers at different inlet pressures of oxygen and air. International Journal of Refrigeration, 32, 1626-1633.

Liew, R., Michalek, W. R., Kuerten, J. G. M., \& Zeegers, J. C. H. (2011). Droplet behaviour in a Ranque-Hilsch vortex tube. Journal of Physics: Conference Series 318, 052013.

Markal, B., Aydin, O., \& Acvi, M. (2010). An experimental study on the effect of the valve angle of counter flow Ranque-Hilsch vortex tubes on thermal energy separation. Journal of Experimental Thermal and Fluid Science, 34, 966-971.

Michalek, W. R., Liew, R., Kuerten, J. G. M., \& Zeegers, J. C. H. (2011). LES of droplet-laden non-isothermal channel flow. Journal of Physics: Conference Series 318, 042056.

Secchiaroli, A., Ricci, R., Montelpare, S., \& D’Alessandro, V. (2009). Numerical simulation of turbulent flow in a Ranque-Hilsch vortex tube. International Journal of Heat and Mass Transfer, 52, 5496-5511.

Sharma, V. S., Dogra, M., \& Suri, N. M. (2009). Cooling techniques for improved productivity in turning. International Journal of Machine Tools and Manufacture, 49, 435-453.

Thomas, M. \& Beauchamp, Y. (2003). Statistical investigation of modal parameters of cutting tools in dry turning. International Journal of Machine Tools and Manufacture, 43, 1093-1106.

Xue, Y., Arjomandi, M., \& Kelso, R. (2010). A critical review of temperature separation in a vortex tube. Experimental Thermal and Fluid Science, 34, 13671374.

Xue, Y., Arjomandi, M., \& Kelso, R. (2011). Visualization of the flow structure in a vortex tube. Experimental Thermal and Fluid Science, 35, 1514-1521.

Yalcin, B., Ozgur, A. E., \& Koru, M. (2009). The effect of various cooling strategies on surface roughness and tool wear during soft materials milling. Journal of Materials and Design, 30, 896-899. 
Yilmaz, M., Kaya, M., Karagoz, S., \& Erdogan, S. (2009). A review on design criteria for vortex tubes. Heat Mass Transfer, 45, 613-632.

Yusuf, M., Khairol, A., Napsiah, I., \& Shamsuddin, S (2011). Influence on cutting parameters on surface roughness for wet and dry turning process. Key Engineering Materials, 471-472, 233-238.

Zahari, T., Hani, K., Hideki, A., Raja Ariffin, G., Julirose, G., \& Novita, S. (2010). Linkage of power consumption to design feature on turning process. Proceedings of the 10th WSEAS Int. Conference on Robotics, Control and Manufacturing Technology, ISBN: 978-960-474-175-5 